\title{
Compatibility of Employee Personal Values with the Organisational Culture of an ODL Institution: Some observations from the Zimbabwe Open University.
}

\author{
${ }^{1}$ Daniel Ndudzo \\ ${ }^{1}$ Registrar, Zimbabwe Open University, Zimbabwe
}

\begin{abstract}
The purpose of this research was to investigate the compatibility of the Zimbabwe Open University (ZOU) organisational culture with employee personal values. The study used the quantitative and qualitative research methodology. The questionnaire instrument was used to collect data from one hundred and twenty, (120) employees. The study revealed that team work, professionalism, education, strong work ethic are the dominant personal values among ZOU employees. These values are compatible with the dominant culture at $\mathrm{ZOU}$ which is basically premised on team orientation, commitment to educational empowerment and the upholding of ethical behaviour and professionalism. The research recommended that the ZOU management should promote additional cultural attributes related to participatory decision making of lower level employees, innovativeness and risk taking to improve organisational performance and survive the competitive world market and open communication between top management and employees. The research also recommended that the institution should recognise and reward outstanding employees.
\end{abstract}

\section{Introduction}

The Zimbabwe Open University (ZOU) is the only institution of higher learning established by an Act of the Zimbabwe Parliament Chapter 25.20 with a mandate to preserve, advance and transmit knowledge through the ODL system.

There are many practices within ZOU that tend to keep the ZOU culture alive and can be used to evaluate the cultural fit between the organization and its employees' personal values. Many of the human resource practices such as recruitment and selection, performance appraisal, training, and career development reinforce the organization's culture. If employees' personal values are not compatible with the organisational culture, employees are most likely to leave the organisation and look for different organisations whose cultures they fit better. In contrast, employees who understand and share the organizational culture are better positioned to make choices that match the organisation's goals. When most employees' personal values are compatible with the organization's culture, less time is spent explaining, instructing, and building consensus before trying something innovative. Employees who are well acculturated also find their work to be more meaningful. When a positive relationship exists between the organization's culture and employee's values there is an improvement in employee engagement, employee retention and organizational productivity.

It is therefore necessary to analyse the Person-Organization (P-O) fit which is defined by (Kristof 1996), "as the compatibility of employee personal values with organisational cultural values which are determined when one entity provides what the other needs or wants and if an organization and an employee share similar fundamental characteristics". This involves investigating fundamental organisational characteristics such as values and goals and checking on the ability of the ZOU culture to fulfill its employees' needs or wants such as competitive pay, promotion, recognition and rewards.

\section{Statement of the Problem}

There is not known a study carried out in Higher Education Institutions, especially at ZOU, on the compatibility of employee personal values with organisational culture. This study therefore attempts to assess the compatibility of employee personal values with the culture of the University. ODL human resources management should strive to ensure a fit between its employees and the organisation. Personal values guide the employee's ethical behaviour and these should be compatible with the organisation's culture and values.

\section{Purpose of the Study}

The purpose of the study was to assess the compatibility of the Zimbabwe Open University culture with employee personal values.

\section{Objectives of the study}

The study was guided by the following objectives: 
- To identify the dominant employee personal values at ZOU.

- To assess the extent to which employee personal values match organisational culture at ZOU.

- To recommend action required to improve compatibility of employees' personal values with the ZOU culture.

\subsection{Key Research Questions}

The study sought to address the following questions:

- What are the dominant personal values among ZOU employees?

- To what extent do employee personal values 'match' or fit the ZOU organisational culture?

- What strategies could be used to improve compatibility of employee personal values with the ZOU culture?

\section{Justification of the study}

The ZOU management will have a clearer understanding of the ZOU culture. In addition possible steps will be taken to improve the compatibility of employee personal values with the ZOU culture. This study will enable ZOU and other ODL institutions to make improved hiring decisions leading to longer employee retention, reduced employment costs, increased productivity and profits. Shared values engender trust, bind the workforce and provide a distinct identity for ZOU. It encourages employees to work to their full potential valuing quality over quantity, creativity over conformity and cooperation over competition.

\section{Review of related literature.}

The following theoretical models explain how organisations enhance compatibility of employee personal values with organisational culture.

\section{Attraction Selection Attrition (ASA) Model, Schneiders (1987).}

According to the Attraction Selection Attrition (ASA) model, potential employees are attracted to and recruited by an organization because they possess certain personal characteristics that match the organization's structure, design and culture (Schneider, 1987). The ASA model also predicts that individuals who do not possess the desirable personal characteristics could be hired but they are likely to leave voluntarily or involuntarily. The ASA process would therefore yield a somewhat homogeneous workforce that is matched with its organization on a variety of dimensions such as values, personality, goals, needs, abilities, etc. Southwest Airlines (SWA) is an example of a company that successfully applied the Attraction Selection Attrition (ASA) model to align employee values with organisational culture. Milliman et-al (2002) observed that SWA's organisational values were openness, friendliness, joy, humor, teamwork, empowerment, family sense, etc. The company gave priority to the fit of the applicants' values to its organisational values rather than their technical abilities. In order to test new applicants the company executed group interviews where the applicants' individual behavior was examined, especially their abilities to be friendly, to tell jokes, to demonstrate teamwork, etc.

\section{Cultural Congruence Model, Schein (1992)}

The Cultural Congruence Model by (Schein 1992) attempts to determine the right "fit" between the individual and the culture of the organisation. This model is based on the belief that if an organization's culture reinforces its mission and its people believe in it, the organization is more effective. Compatibility of employee values and organisational culture can be measured by overall organizational performance, employee satisfaction, quality of work, customer satisfaction, and earnings/revenues. To measure this congruence, one must first determine the artifacts, values, and basic assumptions of an organization. Once these basic determinants of culture are assessed, they can be analyzed in terms of their "fit" with the mission and people. This analysis can take the form of data collection (through observation, surveys, group meetings, and individual patterned interviews), comparative analysis (real stories versus espoused values), and gap analysis (determining where the culture does not reinforce the mission of the organisation). This model also determines changes that must be made in the organization's culture. For instance, if an organization states that one of its key values is innovation and learning, but does not reward people who acquire additional degrees, does not schedule or pay for training, one would assume there is a congruency gap between the organisational values and the artifacts.

\section{Research Methodology}

The paper is based on an interpretivist epistemological framework. This framework influenced the researcher to adopt a qualitative research paradigm. The questionnaire instrument was used to collect data from the Zimbabwe Open University employees. The researcher carried out face to face interviews with the human 
resources personnel and other employees at ZOU. Questionnaires were distributed to a total of one hundred and twenty, (120) employees. The study used the random sampling technique to select participants for the study. The researcher adopted the random sampling technique because every employee of ZOU had an equal chance of participating in the survey thereby reducing chances of bias. The researcher addressed potential participants about their willingness to participate in the study by describing its purpose and potential outcomes

\section{Discussion Of Findings}

Fig 1.1 ZOU recruits candidates with values that fit the ZOU culture

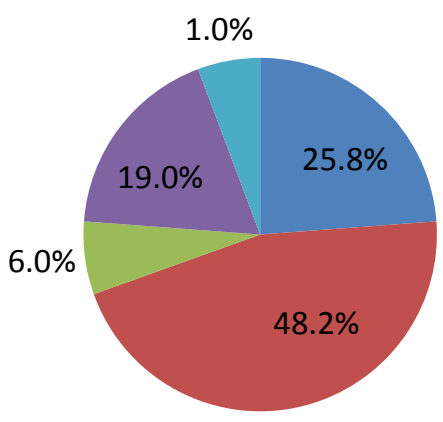

- Strongly agree

agree

Not sure

Disagree

Strongly disagree

The study revealed that $74 \%$ of the respondents agreed that ZOU recruits candidates with values that fit the institution's culture. This is evident in the ZOU human resource procedure manual and the Strategic Plan. These two documents emphasize openness, friendliness, teamwork, recruitment of suitable and competent candidates who have core values that fit the ZOU organisational culture. Making inquiries of the applicant's work philosophy and work habits during the interview process assists management in choosing the most suitable candidate. All new candidates undergo an induction process in order to acquire the institution's culture.

\section{ZOU has got a strong code of ethics}

The research revealed that $87 \%$ of the respondents indicated that most ZOU employees value the ZOU code of ethics. The ZOU Strategic Plan emphasizes the observance of a strict moral code of ethics that embraces transparency, commitment, integrity, confidentiality and impartiality. Personal interviews with human resources personnel revealed that ZOU values employees who are morally upright and honest. Employees who value such practices would fit well into the University culture and strive to promote organisational effectiveness.

Fig 1.2 Staff is motivated by the staff development facility at ZOU.

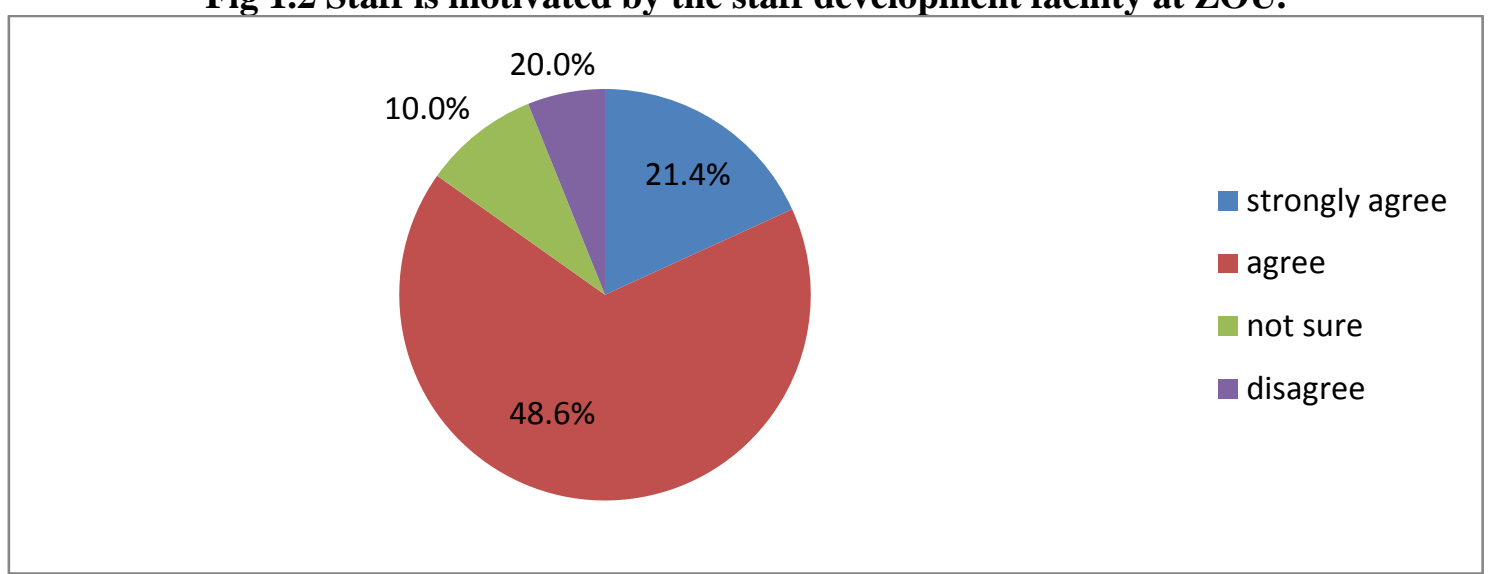

The research revealed that most employees, (70\%) are motivated to improve their educational qualifications. The study noted that employees at ZOU are not leaving the institution maybe due to the availability of opportunities for career development within the organization. Thus the employee's values on career development are compatible with ZOU's staff development training policy which provides an opportunity for staff to upgrade their academic qualifications.

\section{Involvement of lower level employees in key decision making}

The research revealed that most employees at ZOU value participatory decision making. However, most of the respondents, $(70 \%)$ emphasized that employees were rarely engaged in the corporate strategy 
formulation process. Strategies that are formulated by the ZOU top management may not have been solicited from employees at lower levels. According to Magner et al. (1996) employees are motivated to stay longer in positions where they are involved in some level of the decision making.

Fig 1.3 Lack of Open Communication at ZOU.

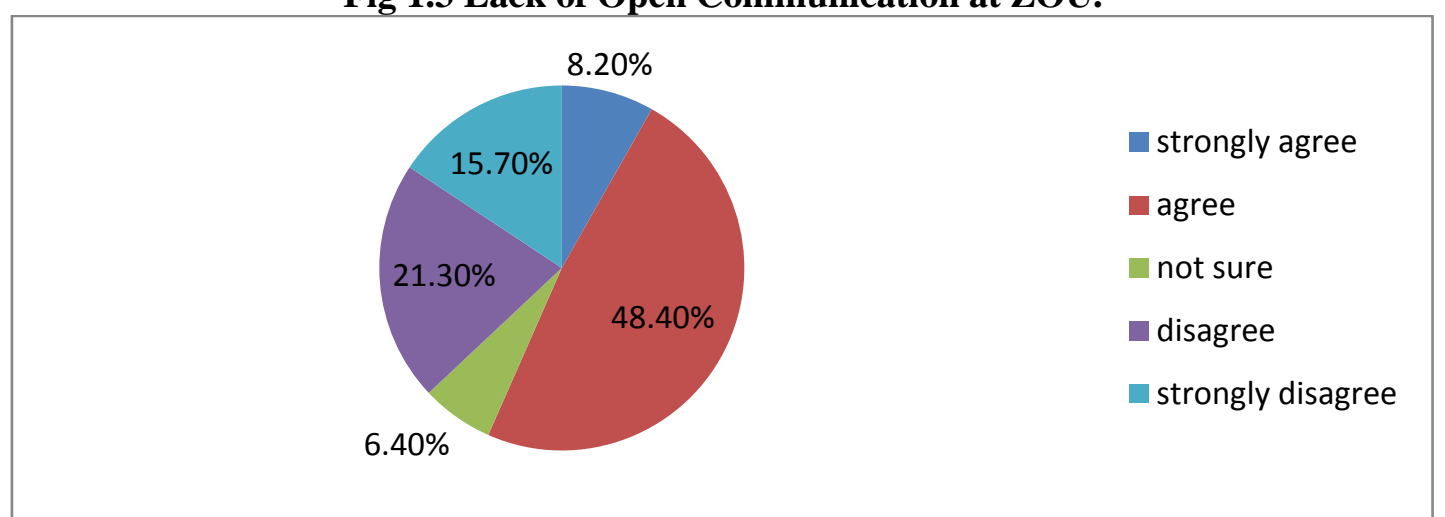

The study indicated that $56.6 \%$ of the respondents felt that ZOU may not have open communication between management and employees. The study highlighted that most ZOU employees (67\%) value open communication. However poor communication seems to be prevalent in the institution. The research revealed that communication breakdown was common as evidenced by the failure of management to openly advise staff on salary delays. The study revealed that communication was generally vague, leading to confusion and as a result employees convey messages incorrectly through grapevine. An organizational culture must support open communication between individuals, teams and departments to improve employee engagement, (Martins 2006). For instance when a manager does not openly communicate with his or her employees the employee may feel abandoned which could lead to increased employee disengagement, (Richmond et al. 1982).

\section{Employee innovation vs. the ZOU structure}

The research confirmed that most ZOU employees, (68\%) valued innovativeness. Most respondents, $(64.4 \%)$ however, felt that the institution was weak in terms of promoting an innovative and risk taking culture. The study highlighted that the Zimbabwe Open University has a dominant structure guided by an elaborate set of standardized rules, procedures, and clear lines of decision-making authority. The study indicated that that the ZOU culture emphasizes stability where work routine and job duties are largely predictable and not likely to change over a long period of time. The hierarchical decision-making system may create feelings of powerlessness and resentment in those excluded from the process thus reducing innovativeness among employees. This line of thought is supported by Visser et al. (2005) who state that a centralised decision making approach suffocates employee individualism, and as such militates against the compatibility of employees' personal values with the organisational culture. Therefore, an organizational culture with strict controls may inhibit risk taking and consequently result in demotivation of employees.

\section{Length of service vs. employee satisfaction with organisational culture}

The research confirmed that $57.6 \%$ of the respondents have served the Zimbabwe Open University for more than 5 years. This shows an increase in the retention of staff from the 80\% attrition rate of 2006-2008 to about $0.5 \%$ of June 2013. Schein (1992) states that employees with values that match corporate culture are likely to stay longer at an organisation. Schein (1992) further states that when an individual's values do not match corporate culture, the employee may leave earlier than an employee whose values match with the corporate culture. Thus, the fact that most respondents indicated that they had stayed for more than 5 years at ZOU may probably mean that employee personal values are compatible with the ZOU organisational culture. This is supported by Autry and Wheeler, (2005) who state that the longer an employee spends in any culture, the more likely that the employee values are to align with the company policy, procedures and philosophy. When asked, "Why employees continued serving ZOU", most respondents, (73\%) indicated that they were motivated to stay by the learning culture at ZOU where employees and their dependants pursue educational programmes with ZOU for free. This shows that ZOU's learning culture is compatible with employees' values on career development. ZOU's emphasis on employee growth and providing the opportunity to learn has ultimately brought a sense of loyalty from employees. 


\section{Professionalism}

The study observed that $65 \%$ of the respondents indicated that most employees at ZOU valued professionalism. In support of this, $75 \%$ of the respondents highlighted that the ZOU culture was strong in upholding professionalism at the workplace. Professional behavior includes learning every aspect of a job and doing it to the best of one's ability. Professionals are enthusiastic about their work and optimistic about the organization and its future. The study revealed that ZOU employees speak and dress in a world class manner and are detail oriented to maintain an image of a World Class University. Employees at ZOU, as professionals, are able to accept constructive criticism from management, learn from their mistakes and continue to improve their performance through varying degrees of innovation and creativity.

\section{Lack of rewards and recognition.}

The research revealed that most of the respondents, (84\%) expected a reward as a way of acknowledging outstanding performance. However, most employees (78\%) highlighted that the Zimbabwe Open University is not recognizing and rewarding outstanding employees. This factor may account for the lack of motivation found among some members. Though the Zimbabwe Open University Strategic Plan (2010-2014) emphasizes on adopting the Incentive System as a measure to reward outstanding employees, the institution has not yet implemented this strategy. The failure to recognize and acknowledge employees' performance has a very detrimental effect on employees' engagement. The research revealed that $75.7 \%$ of the respondents indicated that ZOU's current performance appraisal system is not effective and efficient. The absence of a criterion for the allocation of rewards and status which outlines what behaviour is rewarded and what behavior is punishable may suggest that the organisation does not value the incentivisation of its staff which is incompatible with the employees' values of recognition awards.

\section{Fig 1.4 Employees value teamwork at ZOU}

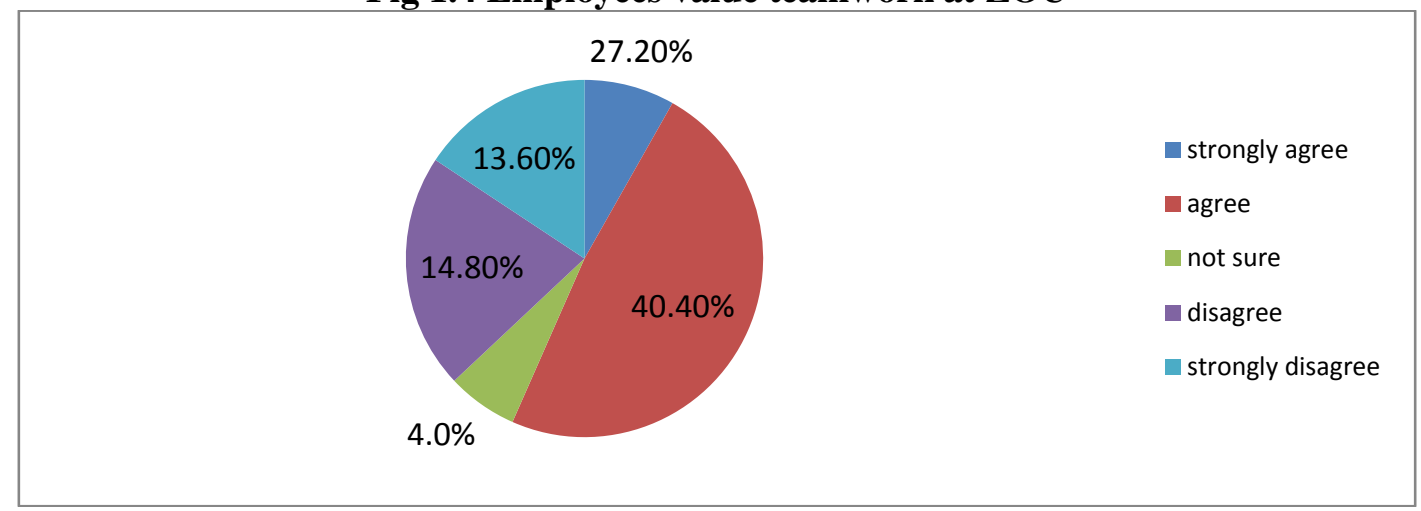

This study observed that $67.6 \%$ of the respondents were of the opinion that employees at ZOU value teamwork. This is consistent with earlier studies that identified team work as a dominant feature of the ZOU culture. The study highlighted that team orientation at ZOU has led to a high rate of employee interaction and enthusiasm which positively impacts on employee morale. Newman and Nollen (1996) reported that work units perform better when their team orientation practices are compatible with the employee personal values. The study revealed that employees at ZOU are strong in group-orientation, ties between people are tight, relationships are firmly structured and individual needs are subservient to the collective needs.

The findings of this research assisted in revealing the compatibility of the ZOU culture with employees' personal values. Employees highlighted their own feelings concerning how they viewed the relationship between their personal values and the organisational culture.

\section{Conclusion}

The research revealed that, to a larger extent, the ZOU culture is compatible with employees' personal values on certain factors such as upholding team work, professionalism, work ethics, career development, recruitment and selection of suitable candidates. It is hoped that organisational performance would improve if the Zimbabwe Open University improves on issues such as open communication, innovativeness and risk taking and participative decision making. These findings if implemented enable the institution to develop appropriate interventions to enhance its ability to achieve compatibility of employee personal values with organisational culture. Finding the best fit between employees' personal values and the organisational culture is also critical to maximizing employees' productivity and creativity. 


\section{Recommendations}

Basing on the findings of this study the following recommendations were suggested:

- From the sentiments raised in this study, it seems that many low level employees do not participate in key decision making bodies like Council, Senate and other Committees at ZOU. Management should therefore promote participatory decision making where lower level employees and middle managers are also consulted on key decisions.

- The University should promote an innovative culture that encourages and rewards innovativeness and risk taking among employees.

- The University should implement the incentive policy as stated in the ZOU Strategic Plan (2010-2014) to improve employee engagement.

- The institution should emphasise on a performance based culture that values hard work, initiative, innovative, risk taking, innovation and creativity.

- The study also recommends further research regarding the alignment of employee personal values with organisational culture. The research will further assess whether a dynamic "fit" exists between employee personal values and organisational culture which allows the institution to perform at optimum levels given that employees are the most important asset of any organisation.

\section{Journals}

\section{References}

[1]. Milliman, J. (2002). Cross-Cultural Performance Feedback in Multinational Enterprises: Opportunity for Organizational Learning. Human Resource Planning, Vol.25, No.3, p. 29-43.

[2]. $\quad$ Shein, Edgar (1992). Organizational Culture and Leadership: A Dynamic View. San Francisco, CA: Jossey-Bass. pp. 9.

[3]. Schneider, B. (1987), "The people make the place", Personnel Psychology, Vol. 40 No. 3, pp. 437-53.

[4]. Magner, N., R.B. Welker and G.G. Johnson, 1996. The interactive effects of participation and outcome favourability on turnover intentions and evaluations of supervisors. J. Occup. Org. Psychol., 69: 135-143.

[5]. Richmond, V.P., McCrosley, J.C., \& Davis, L.M. (1982). Individual differences among employees, management communication style and employee satisfaction: Replication and extension. Human Communication Research, 8,170-188.

[6]. Visser, D.J., de Coning, T.J. and Smit, E.M. (2005), "The relationship between the characteristics of the transformational leader and the entrepreneur in South African SMEs", South African Journal of Business Management, Vol. 36 No. 3, pp. 51-63.

[7]. Autry, C.W. and Wheeler, A. R. (2005) Post-hire Human Resource Management Practices and Person-0rganization Fit: A study of blue-collar employees. Journal of Managerial Issues, 17, (1), pp58-75

[8]. Zimbabwe Open University Strategic Plan (2010-2014)

[9]. Newman, K. L., \& Nollen, S. D. (1996). Culture and congruence: The fit between management practices and national culture. Journal of International Business Studies, 27, 753-779.

\section{Books}

[10]. Kristof, A.L. (1996). Person-organization fit: An integrative review of its conceptualizations, measurement, and implications. Personnel Psychology, 49, 1-49.

[11]. Schneider, Benjamin, ed. Organizational Climate and Culture. San Francisco: Jossey-Bass, 1990.

[12]. Martin G, Hetrick S (2006), Corporate Reputations, Branding and People Management: A Strategic Approach to HR, Butterworth-Heinemann. 